\title{
Chicken Swarm Optimization based PV-STATCOM for Power Compensation in Hybrid PV/WT System
}

\author{
K. Sudarsan ${ }^{a}$, and G. Sreenivasan ${ }^{b}$ \\ aDepartment of EEE, Research scholar, JNTUA University, Anantapuramu, \\ bepartment of EEE, Professor, Srinivasa Ramanujan Institute of Technology, Anantapuramu.
}

Article History: Received: 11 January 2021; Accepted: 27 February 2021; Published online: 5 April 2021

\begin{abstract}
Today's the Energy changes like air contamination and a dangerous atmospheric deviation are increases. To direct these troubles the sustainable power sources are presented. PV ranch generate power throughout daytime and totally latent for the period of nighttime. During daytime the inverter is used for authentic power creation and for the period of nighttime it is used to satisfy the need. For the examination of PV-STATCOM it is anticipated with calculation, such as The CSO calculation is utilized to accomplish the organize of parameters like Voltage, current, and Powers. The Control Strategies are endorsed through MATLAB/Simulink Platform So as to assess the convenience of the projected strategy, this is contrasted with the possible technique like PSO method.
\end{abstract}

Keywords: PV-STATCOM, PSO (Particle Swarm Optimization), CSO (Chicken Swarm Optimization)

\section{Introduction}

Energy is the key aspect for urbanization, monetary new development and enhancement of individual fulfillment (Hosseini, 2020). To sidestep the SSR in control structures, the employ of FACTS plans has been envisioned (Jiang, 2019; Ranjeeth, 2020) The sturdiness of the SSSC and its regulator is affirmed in this paper by oppressing an un symmetrical fault. The evaluation of the belongings of SSSC type regulator is verified when it is presented to an symmetrical fault on transmission line (Kanaga, 2021). A partial request corresponding regulator type UPFC is examined to moist out sub concurrent movements in generator shaft owing to SSR (Murugan, 2020; Rahim, 2020; Ranjeeth, 2019).

Introduces a new energy control for a grid related inverter. The examinations are observed for the collections of SMIB structures (Zhang, 2020; Singh, 2019; Aroulanandam, V. V.,2019).

Consequently the RSC controlers of DFIG were utilized (Chikohora, 2020; Sekaran, 2020;Shankar, 2020). For the evaluating the introduction of controllers in damping SSR, a period repeat assessment is used (Sampath Kumar, 2020; Latchoumi, 2017;Rajan, 2020). A WAMS based normal regulator is used to in PV plant to wet the SSR (Irsalinda, 2017).

\section{PV-STATCOM based control configuration}

In daytime the PV framework and wind framework is producing power for culmination the load. The night time, the wind and STATCOM full fills the need in light of the fact that in the night time the PV close planetary structure is missing (Fardad, 2019; Latchoumi, 2013; Aleem, 2020). The anticipated development is outlined in the Fig 1. The PV and Wind is joined for generating capacity to the load request. The capacitors are shown in fig 1 utilized for delicate exchanging and diminish voltage spikes. 


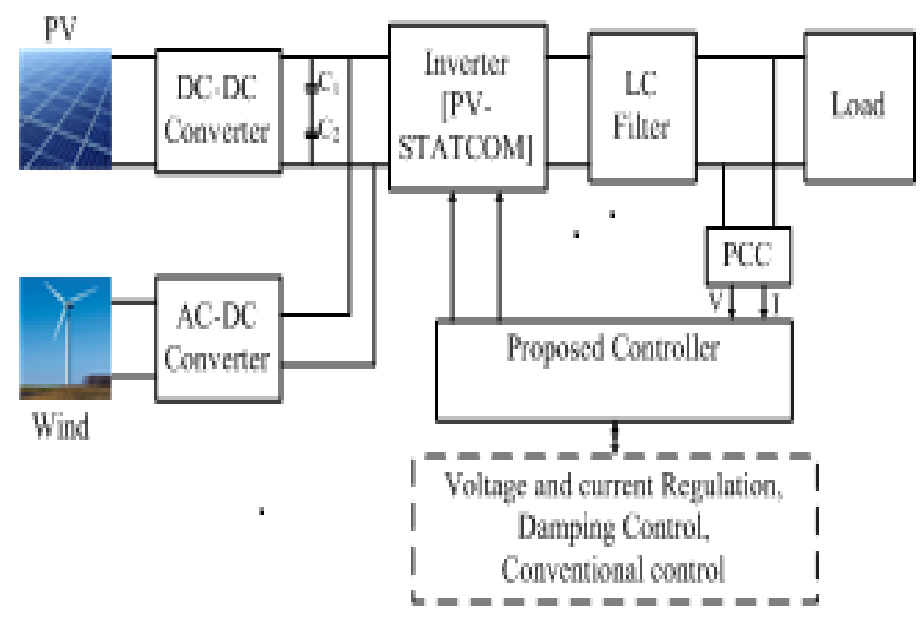

Figure. 1: Block diagram for projected method

\subsection{CSO algorithm}

The CSO calculation is used to limit the error standards of the parameters. The CSO calculation, the best wellness esteem is allocated to rooster cloud and the most exceedingly awful wellness esteem is allocated to chick cloud. The remainder of the qualities are allocated to hen cloud (Dug, 2019).

Step 1: Initialise the population, errors and change in errors of the parameters

$$
x_{i, j}^{t+1}=l r b+\operatorname{Rand}(u r b-l r b)
$$

Step 2: calculate the robustness and initialise the best personal position

$$
F=\operatorname{Minimum}\left(E_{v}, E_{I}, E_{P}, E_{Q}\right)
$$

Step 3: Grade the strength of the chicken and determine the relation.

$$
x_{i, j}^{t+1}=x_{i, j}^{t}+S 1 * \operatorname{Rand} *\left(x_{r 1, j}^{t}-x_{i, j}^{t}\right)+S 2 * \operatorname{Rand} *\left(x_{r 2, j}^{t}-x_{i, j}^{t}\right)
$$

Step 4: Modernize the position of the Roosters, the hen and the chick.

$$
\begin{aligned}
& x_{i, j}^{t+1}=x_{i, j}^{t} *\left(1+\operatorname{Rand}\left(0, \sigma^{2}\right)\right.
\end{aligned}
$$

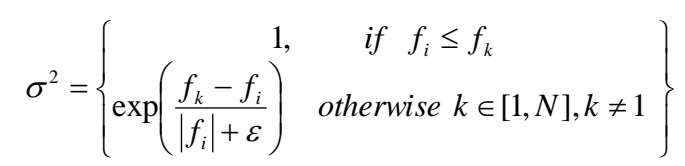

Step 5: modernize the best personal position $N_{\text {best }}$

Step 6: At $t=t+1$, if the stop situation is meet, output is most favorable; or else, go to step 3 .

\section{Results and Discussions}

In this segment, the presentation of the projected regulator is explored in Fig.2. The projected framework is utilized to control the parameters and improve the power for the period of PV-STATCOM. 


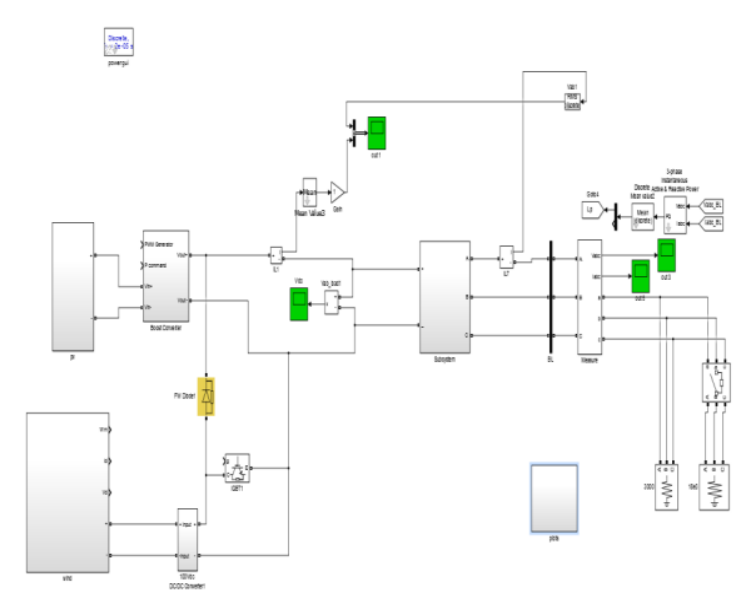

Figure 2: Simulation model of projected method

The projected regulator of CSO calculation is utilized to improve the STATCOM arrangement. The assessment of the execution consequences are watched.

\subsection{Performance Analysis}

The recreated consequence of the projected regulator is analyzed in particular cases. The cases are,

\section{Case 1: PV STATCOM operation during day time}

The presentation of PV STATCOM by means of CSO and PSO calculations are analysed openly subject to the simulation results during daytime and nighttime. For this circumstance, the daytime the PV power is dynamic owing to the irradiance stage is high. The daytime the total power is remunerated the load demand thought to be predictable of $8000 \mathrm{~W}$. The Load power is outlined in the Fig. 3. For the period of daytime, the generated powers are compensated the load demand appeared in Fig. 4 and 5.

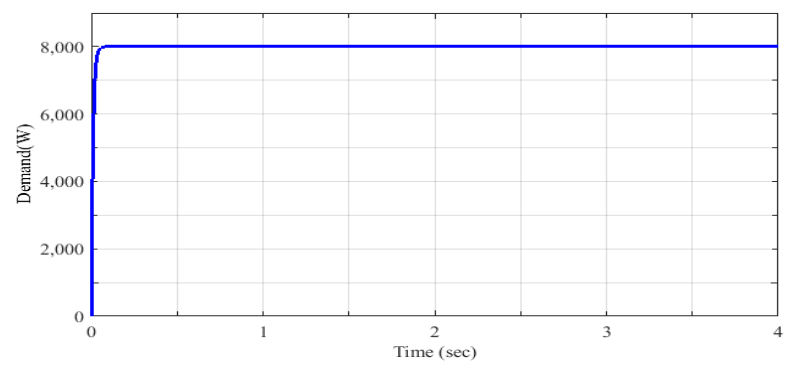

Figure 3: Analysis of load demand power

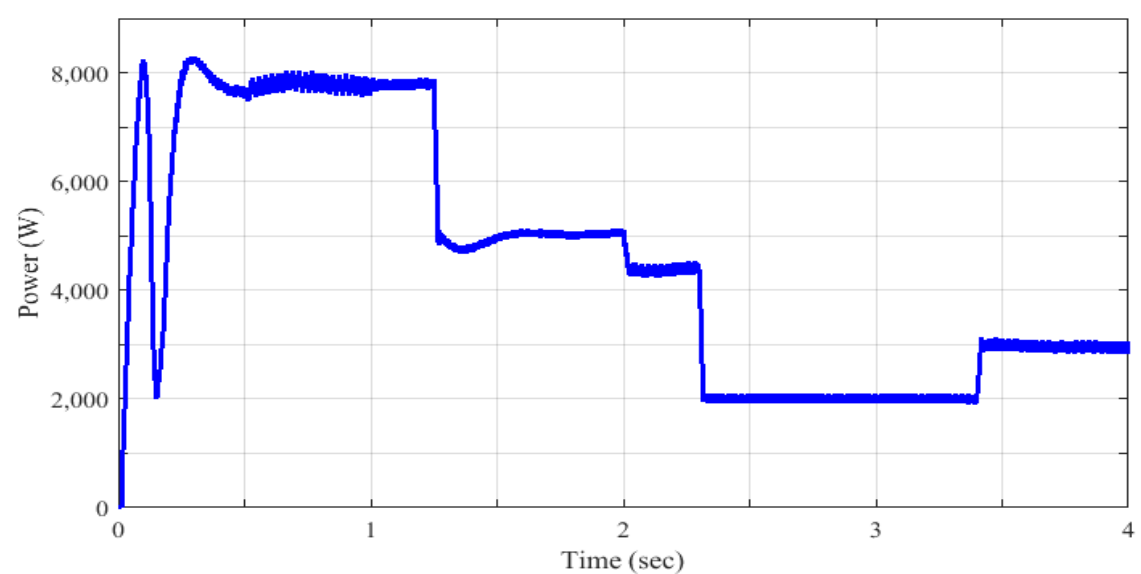

Figure 4: PV solar generated power 
Fig. 6(a) shows the Generated Power with load demand. The reference power is $8000 \mathrm{~W}$. Using the projected calculation, the load request is meet by the Generated powers. So additionally, the load is changed subsequent to the exacting time second, and subsequently anticipated the powers showed up in Fig. 6(b)

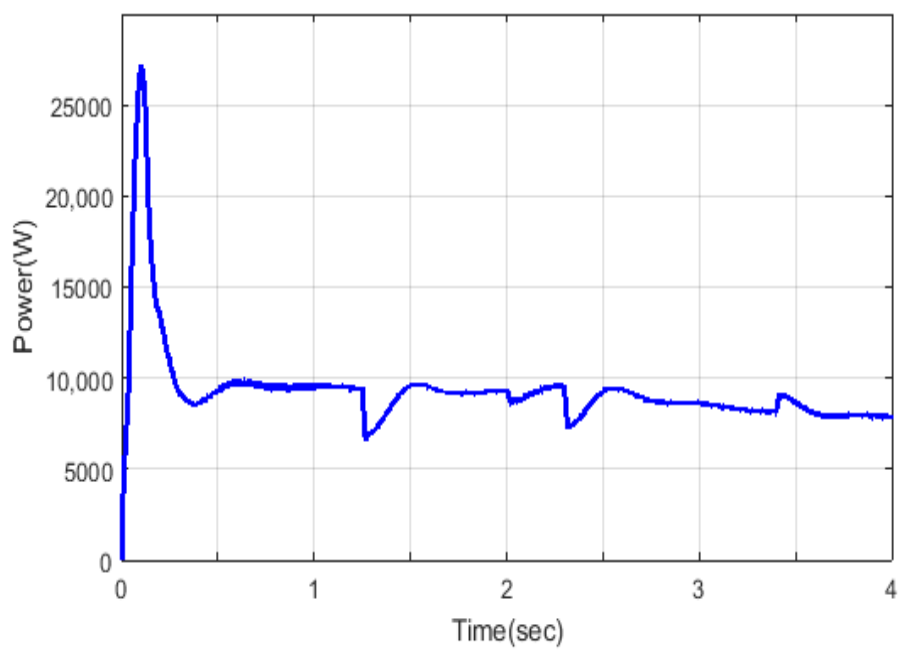

Figure 5: wind generated power

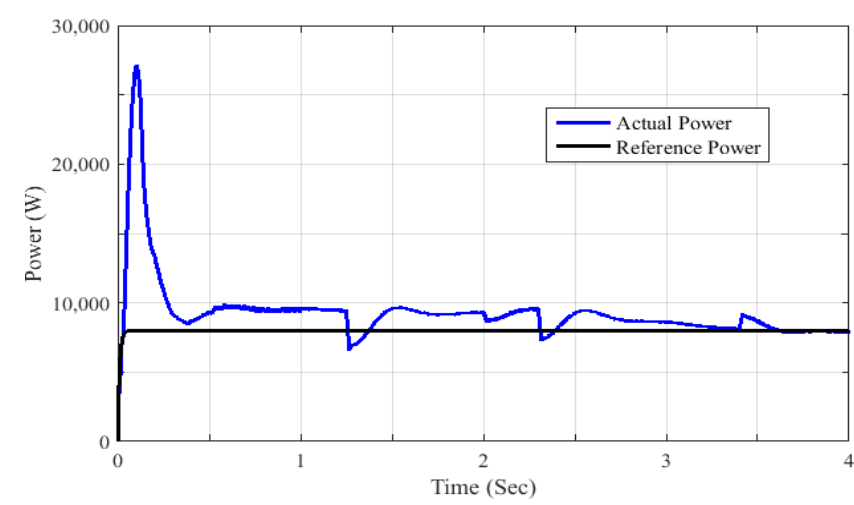

(a)

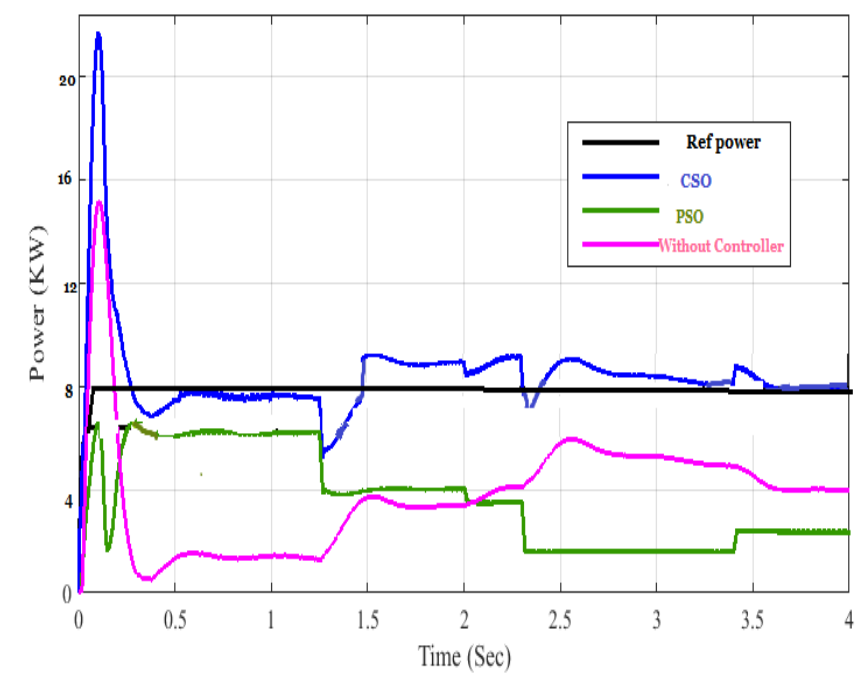

(b) 
Figure 6: (a) Generated power with load demand (b) Comparative analysis

\section{Case 2: PV STATCOM operation during nighttime}

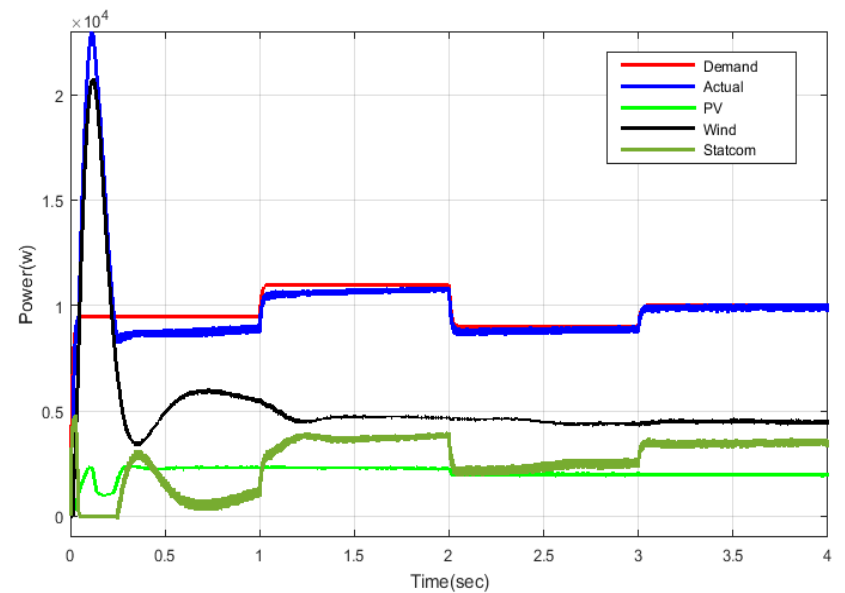

Figure 7: Generated power with Load demand

For this circumstance assessment, the load request isn't consistent and change between $9000 \mathrm{~W}$ to $11000 \mathrm{~W}$. The figure shows the Load request assessment of the nighttime. Using the projected strategy, the load request is met in the nighttime showed up in the figure 7. Computation time for various methods shown in figure 8 . Table 1 shows the performance anaysis of various techniques

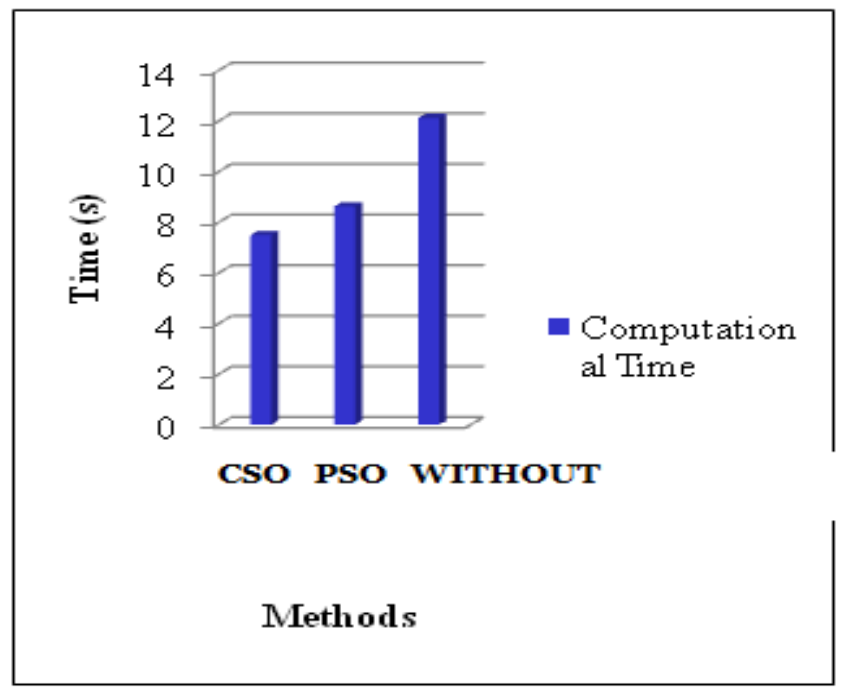

Figure 8: Computation time for various methods 
Table 1 : Performance analysis

\begin{tabular}{|c|c|c|c|c|c|c|c|c|c|c|}
\hline \multirow[t]{2}{*}{$\begin{array}{l}\text { Mode of } \\
\text { Operation }\end{array}$} & \multicolumn{2}{|l|}{ Cases } & \multirow{2}{*}{$\begin{array}{l}\text { Solarpower } \\
\text { (W) }\end{array}$} & \multirow{2}{*}{$\begin{array}{l}\text { Wind } \\
\text { Power } \\
\text { (W) }\end{array}$} & \multirow{2}{*}{$\begin{array}{l}\begin{array}{l}\text { Load } \\
\text { demand }\end{array} \\
\qquad(\mathrm{W})\end{array}$} & \multicolumn{2}{|c|}{$\begin{array}{c}\text { PV- } \\
\text { STATCOM }\end{array}$} & \multicolumn{3}{|c|}{ Compensated Power } \\
\hline & $\begin{array}{l}\text { Irradiance } \\
(\mathrm{w} / \mathrm{m} 2)\end{array}$ & $\begin{array}{l}\text { Wind } \\
\text { speed } \\
(\mathrm{m} / \mathrm{s})\end{array}$ & & & & $\begin{array}{l}\text { Store } \\
\text { Power } \\
\text { (W) }\end{array}$ & $\begin{array}{l}\text { Injected } \\
\text { Power } \\
\text { (W) }\end{array}$ & $\begin{array}{c}\text { CSO } \\
\text { (Proposed) }\end{array}$ & PSO & Without \\
\hline $\begin{array}{l}\text { Day time } \\
\text { mode } \\
\text { Analysis }\end{array}$ & \begin{tabular}{l}
\multicolumn{1}{c}{300} \\
$\mathrm{w} / \mathrm{m} 2$ to \\
$150 \mathrm{w} / \mathrm{m} 2$ \\
at $0-4 \mathrm{~s}$
\end{tabular} & $\begin{array}{l}\quad 1 \\
2 \\
\mathrm{~m} / \mathrm{s}, \\
\text { to } 8 \\
\mathrm{~m} / \mathrm{s} \\
\quad \text { at } \\
0-4 \mathrm{~s}\end{array}$ & $\begin{array}{l}2000 \\
W- \\
8000 W\end{array}$ & $\begin{array}{r}8000 \\
\text { W- } \\
10000 \mathrm{~W}\end{array}$ & ${ }_{0 W}{ }^{800}$ & $\begin{array}{l}\mathrm{Up} \\
\text { to } \\
4000 \mathrm{~W}\end{array}$ & - & $\mathrm{w}^{7400}$ & $\begin{array}{l}{ }^{67} \\
00 \mathrm{~W}\end{array}$ & $0 \mathrm{~W}^{450}$ \\
\hline $\begin{array}{l}\text { Night } \\
\text { time } \\
\text { mode } \\
\text { Analysis }\end{array}$ & $\begin{array}{c}10- \\
100 \mathrm{w} / \mathrm{m} 2\end{array}$ & $\begin{array}{l}-10^{8} \\
\mathrm{~m} / \mathrm{s}\end{array}$ & $\begin{array}{l}\quad 100 \\
\text { W- } \\
2500 \mathrm{~W}\end{array}$ & W 5000 & $\begin{array}{l}\quad 950 \\
0 \mathrm{~W}, \\
11000 \mathrm{~W}, \\
9000 \mathrm{~W}, \\
1000 \mathrm{~W} \\
\text { at } 0-4 \mathrm{~s}\end{array}$ & - & $\begin{array}{l}\quad \mathrm{Up} \\
\text { to } \\
3500 \mathrm{~W}\end{array}$ & W 10500 & $\begin{array}{l}98 \\
\text { 00W }\end{array}$ & $0 \mathrm{~W}^{800}$ \\
\hline
\end{tabular}

\section{Conclusion}

The control of the PV STATCOM at daytime and nighttime assessment by methods for load variety is explained in this paper. In the identical, the projected procedure simulation with all the parameters have been finished. The suitability of the projected technique was asserted through a comparable examination with different strategies. From the assessment investigation, it has been found that the projected control methodology was very much productive updating the movement of the PV-STATCOM of the scheme than variousstrategies.

\section{References}

1. Aleem, Sk Abdul, S. M. Hussain, and Taha Selim Ustun. (2020). "A Review of Strategies to Increase PV Penetration Level in Smart Grids." Energies 13(3) 636.

2. Aroulanandam, V. V., Latchoumi, T. P., Bhavya, B., \& Sultana, S. S. (2019). Object Detection in Convolution Neural Networks Using Iterative Refinements. Revue d'Intelligence Artificielle, 33(5) 367372

3. Chikohora, Tinashe E., and David TO Oyedokun. (2020). "Sub-Synchronous Resonance (SSR) in Series Compensated Networks with High Penetration of Renewable Energy Sources." In 2020 International SAUPEC/RobMech/PRASA Conference, pp. 1-6.

4. Duc Tung, Doan, Le Van Dai, and Cao Le Quyen. (2019). "Subsynchronous Resonance and FACTSNovel Control Strategy for Its Mitigation." Journal of Engineering.

5. Hosseini, Seyed Rasoul, Mehdi Karrari, and Hossein Askarian Abyaneh. "Performance evaluation of impedance-based synchronous generator out-of-step protection in the presence of unified power flow controller. (2020). " International Journal of Electrical Power \& Energy Systems 114105384.

6. Fardad, Noorolah, Soodabeh Soleymani, and Faramarz Faghihi. (2019). "Voltage Sag Investigation of Microgrid in the presence of SMES and SVC." Signal Processing and Renewable Energy 3(1) 23-34.

7. Irsalinda, Nursyiva, Aris Thobirin, and Dian Eka Wijayanti. "Chicken swarm as a multi step algorithm for global optimization." (2017). Int. J. Eng. Sci. Invention 6(1) 8-14

8. Jiang .H et al., (2019). "Application of UPFC to mitigate SSR in series-compensated wind farms," in The Journal of Engineering, 2019, no. 16, pp. 2505-2509, 3 doi: 10.1049/joe.2018.8533.

9. Kanaga Suba Raja .S, A. Sathya,S. Karthikeyan,T. Janane (2021) 'Multi cloud-based secure privacy preservation of hospital data in cloud computing', International Journal of Cloud Computing (Inderscience Enterprises Ltd), ISSN 2043-9989, 10(1/2), pp. 101-111. https://doi.org/10.1504/IJCC.2021.10036376

10. Latchoumi, T. P., Loganathan, J., Parthiban, L., \& Janakiraman, S. (2016, August). OFS method for selecting active features using clustering techniques. In Proceedings of the International Conference on Informatics and Analytics (pp. 1-4). 
11. Latchoumi, T. P., \& Parthiban, L. (2016). Secure Data Storage in Cloud Environment using MAS. Indian Journal of Science and Technology, 9, 24-29.

12. Latchoumi, T. P., \& Kannan, V. V. (2013). Synthetic Identity of Crime Detection. International Journal, 3(7), 124-129.

13. Latchoumi, T. P., Kannan, V. V., \& Ezhilarasi, T. P. (2013). Leasing Processing Power from Mid network using Wireless Communication. International Journal, 3(5), 191-199.

14. Murugan, S., Jeyalaksshmi, S., Mahalakshmi, B., Suseendran, G., Jabeen, T. N., \& Manikandan, R. (2020). Comparison of ACO and PSO algorithm using energy consumption and load balancing in emerging MANET and VANET infrastructure. Journal of Critical Reviews, 7(9).

15. Rahim, Robbi, S. Murugan, Reham R. Mostafa, Anil Kumar Dubey, R. Regin, Vikram Kulkarni, and K. S. Dhanalakshmi. (2020). "Detecting the Phishing Attack Using Collaborative Approach and Secure Login through Dynamic Virtual Passwords." Webology 17(2).

16. Rajan, P. T., and G. P. Ramesh. (2020). "Mitigation of Power Quality in Wind DFIG-Fed Grid System." In Intelligent Computing in Engineering, pp. 615-624. Springer, Singapore.

17. Ranjeeth, S., Latchoumi, T. P., Sivaram, M., Jayanthiladevi, A., \& Kumar, T. S. (2019, December). Predicting Student Performance with ANNQ3H: A Case Study in Secondary Education. In 2019 International Conference on Computational Intelligence and Knowledge Economy (ICCIKE) (pp. 603607). IEEE.

18. Ranjeeth, S., \& Latchoumi, T. P. (2020),Predicting Kids Malnutrition Using Multilayer Perceptron with Stochastic Gradient Descent, 34(5), Revue d'Intelligence Artificielle, 631-636

19. Sampathkumar, A., Murugan, S., Sivaram, M., Sharma, V., Venkatachalam, K., \& Kalimuthu, M. (2020). Advanced Energy Management System for Smart City Application Using the IoT. In Internet of Things in Smart Technologies for Sustainable Urban Development (pp. 185-194). Springer, Cham.

20. Sekaran, K., Rajakumar, R., Dinesh, K., Rajkumar, Y., Latchoumi, T. P., Kadry, S., \& Lim, S. (2020). An energy-efficient cluster head selection in wireless sensor network using grey wolf optimization algorithm. TELKOMNIKA, 18(6), 2822-2833.

21. Shankar, G., Latchoumi, T. P., Chithambarathanu, M., Balayesu, N., \& Shanmugapriya, C. (2020). An Efficient Survey on Energy Conservation System with Video Surveillance. Journal of Xian University of Architecture and Technology, 12(7), 100-106.

22. Singh, Ayush Kumar, and Amir Hussain Idrisi. (2019). "Evolution of Renewable Energy in India: Wind and Solar." Journal of The Institution of Engineers (India): Series C 1-13.

23. Zhang, Weichao, Xiangwu Yan, and Hanyan Huang. (2020). "Performance Tuning for Power Electronic Interfaces Under VSG Control." Applied Sciences 10(3). 953. 